\title{
Word of Mouth from Left-Behind Children in Rural China: Exploring Their Psychological, Academic and Physical Well- being During COVID-19
}

\author{
Chunhai Gao $^{2} \cdot$ Endale Tadesse $^{1}$ (D) $\cdot$ Sabika Khalid ${ }^{1}$ \\ Accepted: 31 January 2022 / Published online: 26 February 2022 \\ (C) The Author(s), under exclusive licence to Springer Nature B.V. 2022
}

\begin{abstract}
COVID-19 has had considerable effects on people's lives worldwide, particularly left-behind children in China as they tragically witnessed the outbreak. From the outset, millions of left-behind children in rural areas experienced extensive physical and psychological disturbances because their migrant parents who lived in the city or another province could not be with them. This study explored the psychological, academic, and physical well-being of rural left-behind children during COVID-19. We captured the experiences of 10- to 15-year-old children and adolescents who were left behind by their migrant parents before the COVID-19 outbreak. The results of the present study suggest that left-behind children have exhibited severe psychological illnesses since the pandemic has limited their social interactions with peers and increased improper caretaking from grandparents.
\end{abstract}

Keywords COVID-19 · Left-behind children · Psychological adjustment · Academic adjustment $\cdot$ Physical well-being

\section{Introduction}

Rural to internal urban migration in China brought massive changes in migrant family functioning (Jia and Tian, 2010; Jingzhong and $\mathrm{Lu}, 2011 ; \mathrm{Hu}, 2016$; $\mathrm{Mu}$ and $\mathrm{Hu}$, 2016; Liang et al., 2017; Hu, 2019; Tian et al., 2017; Xiaofeng et al., 2018; Chen et al., 2019; Lu et al., 2019; Zhang et al., 2019; Liu et al., 2020; Shi et al., 2021). Since

Endale Tadesse

endaletadesse2017@gmail.com

1 Faculty of Education, Educational Leadership and Management, Southwest University, No.2 Tiansheng Road Beibei District, 400715 Chongqing, P.R. China

2 Faculty of Education, Shenzhen University, Shenzhen, China 
the early 1980s, China's urbanization expansion plan and relaxing household registration system (hukou) have stimulated economic growth (Su et al., 2017), attracting rural peasant workers to urban areas to seek better job opportunities and lifestyles (Jingzhong and Lu, 2011; Wen and Lin, 2012; Wu and Zhang, 2017). This dramatic migration decreased the impoverishment of rural areas and encouraged laborers to move from rural to urban areas to satisfy the cities' need for labor (Jingzhong and Lu, 2011; Wen and Lin, 2012; Wu and Zhang, 2017; Su et al., 2017; Liu et al., 2020; Shi et al., 2021).

This process led to many left behind children (LBC) in rural areas who were left with caregivers, typically grandparents and relatives, while one or both parents migrated to cities (Jingzhong and Lu, 2011). The relevant evidence shows that the number of LBC exceeds 61 million, almost one-fifth of all children living in China (All-China Women's Federation, 2013; Zhang et al., 2014). Studies call these children who stay behind in rural village households with their migrant parents' relatives or their grandparents for more than six months "left behind children" and "floating children" and the migrant parents "work away parents" (Jia and Tian, 2010; Wen and Lin, 2012; Mu and Hu, 2016; Liang et al., 2017; Chen and Jiang, 2019; Fu and Zhu, 2020). Many questions exist regarding why these migrant parents could not take their LBC and instead left them behind. The answer is that the hukou policy states that if the child of a migrant parent intends to receive compulsory education (grades 1-9) in a location other than his or her birth or household hukou registration district, he or she must pay a large enrollment fee (e.g., to attend an urban school), which places a strain on migrant parents. Therefore, most migrant parents leave their children behind with a family member so that the children can pursue their compulsory education for free (Su et al., 2017; Wu and Zhang, 2017; Xiaofeng et al., 2018; Chen et al., 2019; Lu et al., 2019; Zhang et al., 2019).

Unfortunately, a large body of evidence affirms that due to abusive caretaking and early age, the separation of LBCs from their parents causes considerable psychological (Jia and Tian, 2010; Mu and Hu, 2016; Wang et al., 2021), academic (Liu et al., 2020; Mao et al., 2020; Liu et al., 2021), and health (Gao et al., 2010) issues. Moreover, the intensive working hours and job engagement of migrants make them unable them to visit their children (Tang and Li, 2021). Long parental absence damages the parent-child relationship due to less communication and attachment time and means (Zhang et al., 2014; Wang et al., 2019; Liu et al., 2020; Shi et al., 2021). A previous study noted that parental migration leaves these children in a space of solitude, silence, and sadness (Jia and Tian, 2010). Furthermore, the literature notes that insufficient family care and love from parents causes cognitive and noncognitive problems, such as a lack of self-control, poor social interaction, aggressiveness, self-hate, and health issues in LBC (Jia and Tian, 2010; Jingzhong and Lu, 2011; Gaydosh, 2015; Hu, 2016; Liang et al., 2017; Tian et al., 2017; Fu et al., 2017; Chen and Jiang, 2019; Guan and Deng, 2019; Chen et al., 2019; Fu and Zhu, 2020; Gao et al., 2010; Lu et al., 2019; Hu et al., 2020; Hou et al., 2020; Xiao et al., 2020; Shi et al., 2021). Recent disruptions caused by COVID-19 are massive. The literature has noted that COVID-19 disruptions have affected children's emotional and psychological states (Zhang, 2019; Fontanesi et al., 2020; Wang, 2020; Tang and Tang Li, 2021; Zhao et al., 2021), and children living in rural areas are more vulnerable to mental health 
issues during the COVID-19 outbreak (Li et al., 2021). A United Nations policy brief on the effects of COVID-19 on vulnerable children (homeless children, migrants and minorities, disabilities, street children, and lower SES children) noted that the pandemic negatively affected the psychological states of this particular group of children (Caron et al., 2021; Wang, 2020; Zhao et al., 2021). Another study showed that during COVID-19, more than 300 million children in China experienced difficulty (Zhao et al., 2021). Likewise, a study conducted during the pandemic found that LBC with high COVID-19 fears showed severe insomnia and anxiety symptoms (Chi et al., 2021).

Later literature has found that the consequences of COVID-19 are more severe for families and children who already experience psychosocial problems (Wang, 2020; Tang and Li, 2021; Zhao et al., 2021), including LBC, who are already negatively affected by their parents' internal migration in China (Zhang et al., 2014; Bai et al., 2018; Zhang, 2018; Wang, 2020). Therefore, this study sought to explore the experiences of rural LBC in China, who are the most disadvantaged and marginalized group of children during COVID-19 (Mu and $\mathrm{Hu}, 2016$ ). We focus on how this particular group of children experienced COVID-19 and how their parental support and caregivers helped them sustain their academic, psychological and physical well-being.

\section{Psychological Challenges of LBC}

Previous literature has explored many difficulties of children who are left behind by migrant parents in rural China (Jia and Tian, 2010; Cuong \& Linh, 2015; Mu and Hu, 2016; Liang et al., 2017; Chen et al., 2019; Fu and Zhu, 2020; Guan and Deng, 2019; Gao et al., 2010; Liu et al., 2020; Liu et al., 2021; Wang et al., 2019; Wang et al., 2021). A large volume of evidence has found that LBC are at high psychological risk due to loneliness and feelings of isolation (Jia and Tian, 2010; $\mathrm{Mu}$ and $\mathrm{Hu}, 2016$; Liang et al., 2017; Zhang, 2019; Liu et al., 2020; Shi et al., 2021; Wang et al., 2021). Although the legal guardians of LBC try to compensate for their parental absence by being with them or allowing them to play with their peers, this cannot replace parental absence (Zhang et al., 2014; Shi et al., 2021). Some migrant parents struggle to keep in touch with their LBC in rural areas via social media; this negatively affects average child development (Wen and Lin, 2012; Chen et al., 2019; Shi et al., 2021), and parent-children communication through social media cannot satisfy children's need to receive affection from their migrant parents (Xiaofeng et al., 2018). Good communication between migrant parents and caretakers can reduce the risk of physical and mental problems in LBC (Zhang et al., 2019; Shi et al., 2021).

Poor supervision at home, separation from parents and traditional caretaking from grandparents who may have outdated views of life that do not meet the needs of LBC in modern society can lead LBC to indulge in harmful activities and offensive behaviors (Jia and Tian, 2010; Liang et al., 2017; Wu and Zhang, 2017), such as skipping food, attempts to leave home, and suicidal ideation as well as a high prevalence of smoking and drinking (Goa et al., 2010). Rural LBC aged 7-9 have fewer prosocial behaviors than urban LBC aged 7-16 (Zhang et al., 2019). The bitter realities of LBC and caretaker mistreatment are depicted in a book by $\mathrm{Mu}$ and $\mathrm{Hu}$ that discusses nine 
tragic stories of LBC who were left behind by their parents and developed eccentric dispositions, committed suicide due to anxiety, or died due to accidents and a lack of life safety awareness $(\mathrm{Mu}$ and $\mathrm{Hu}, 2016)$. Another meta-analysis noted that $71 \%$ of LBC in China experienced physical and mental abuse; the riskiest injury was being burned while working in a kitchen and preparing food (Chen et al., 2019). However, such phenomena occur less often among adolescents, and the effects are more damaging for young children (Wang et al., 2019). Most adolescent LBC understand the sacrifices and benefits of parental migration as parents seek to provide the best for their families in terms of security and better future planning $(\mathrm{Hu}, 2019)$.

In addition to sending supportive remittances to their LBC, positive parental communication with their LBC affects children's aggressive and problematic behavior issues (Lu et al., 2019; Zhang et al., 2019). However, an exceptional study found no difference in mental health and well-being between LBC and non-LBC (Zhang et al., 2019). Furthermore, a large body of literature demonstrates the complex and vulnerable situations of LBC, such as poor physical and mental health, weak attachment with peers and parents, poor well-being, behavioral issues, experiences of harassment, lower levels of happiness, exposure to anxiety and depression, and lower academic performance (Mu and Hu, 2016; Chen and Jiang, 2019; Zhang, 2018; Zhang, 2019; $\mathrm{Hu}$ et al., 2020). A few studies examining the influence of COVID-19 on academic performance found that stress and depression were lower in primary school children than in senior school students, although senior school students had to appear for college entrance examinations. In addition, students who were less aware of home quarantine and had no discussion with their parents regarding COVID-19 had a high level of depression, anxiety and fear about COVID-19 (Chi et al., 2021; Tang et al., 2021). Particularly during the pandemic period, these families confronted changes (Wang et al., 2021). A study by Patrick and colleagues on the family context and children's development noted that parental emotional and influential guidance is crucial for preventing disruptive behaviors in children (Patrick et al., 2014). The literature shows that the poor mental health of LBC adversely impacts their academic performance (Wang, 2014; Zhang et al., 2014; Fu et al., 2017; Wu and Zhang, 2017; Hu et al., 2020; Hou et al., 2020; Liu et al., 2021; Mao et al., 2020; Wang et al., 2021).

\section{Academic Challenges of LBC}

Previous literature in China has indicated that the adverse influence of parental absence on academic attainment is more substantial for LBC with only one migrant parent than for LBC with both parents as migrants (Zhang et al., 2014; Fu et al., 2017; Wu and Zhang, 2017; Hu et al., 2020; Mao et al., 2020). Likewise, studies indicate that LBC aged 8-17 have poorer academic performance than their peers (Zhou et al., 2015). Furthermore, maternal migration has a more adverse impact than paternal migration. Maternal absence forces LBC to be occupied with household obligations and daily work that consume their academic time (Cuong and Linh, 2015; Fu et al., 2017; Xiaofeng et al., 2018; Liu et al., 2020; Liu et al., 2021; Mao et al., 2020). Therefore, parental migration places the burden of household chores on children, especially girls, which adversely impacts their academic progress (Meyerhoefer and 
Chen, 2011). Despite this, the study found that the academic performance of LBC is nearly the same as that of children living with both parents. The study conducted indepth quantitative analysis and explored whether children living with parents in rural areas are more involved in farming and household obligations. In addition, LBC have worse than expected academic performance (Zhou et al., 2015). Most importantly, a recent survey study during the pandemic found that due to parental absence during this critical period, the academic performance of LBC was lower (Wang et al., 2021). Nevertheless, few studies examining the influence of COVID-19 on LBC considering their vulnerable position have been conducted (Tang et al., 2021), and few studies have employed qualitative research approaches to determine the experiences of LBC. In contrast, a recent study highlighted no significant difference between the cognitive performance of LBC compared to children living with their parents (Hou et al., 2020), and leaving children behind may have a positive effect if migrant parents' remittance is high (Hou et al., 2020). Remittances may help LBC obtain educational and noneducational resources and facilities (Hou et al., 2020). Migrant parents who send sufficient money to their LBC have high expectations and aspirations, which strongly relate to students' academic achievement (Fan and Chen, 2001).

\section{The Physical Well-Being of LBC}

The physical absence of parents could increase the consumption of unhealthy food among LBC (Tian et al., 2017; Zhang, 2018). However, remittances allow LBC to access quality food, healthcare, and sanitation services (Hou et al., 2020). A study revealed that parents' migration has a positive impact on the growth status of LBC and that the height and weight of male LBC increased after the migration of the mother (Tian et al., 2017). However, another study claimed that with maternal migration, nutritious food consumption is reduced for LBC (Chen et al., 2019). Additionally, compared to children whom the parents did not leave behind, LBC have poor health and nutrition compared to their age group (Tian et al., 2017).

Zhang's (2018) study indicated that most of the LBC who were their study participants were thin due to lower-nutrition food. The study found that low-quality food takes less time for cooking and preparation for LBC. A study explored whether depression through food insecurity among LBC is associated with poor grandparenting styles (Yang and Liu, 2020). LBC's food insecurity is closely associated with school performance and depression (Zhang and Yang, 2019). Because most parents leave their children at an early age, a study noted that LBC aged 3-5 did better than LBC aged 8-10, who had worse health growth (Zhou et al., 2015).

Another study explored whether paternal migration had a negative impact on carbohydrate intake and lowered energy food consumption, especially for female LBC (Tian et al., 2017). Likewise, a cross-sectional study found that a lack of physical activity and an unhealthy diet among male LBC caused overweight and drug addiction problems. In addition, female LBC had more emotional issues (depression and sadness) (Gao et al., 2010). Remittances can support the material welfare of LBC but cannot prevent physical injury and victimization. Due to limited entertainment activi- 
ties, these children spend time engaging in dangerous activities with their peers that have high rates of physical injuries.

\section{Grandparent Caretaking and LBC}

Most migrants' children are cared for by their grandparents in rural China; a recent study estimated that these children constituted $81 \%$ of all LBC (Xiao et al., 2020). A study by Chen and Jiang reported that caretaking arrangements have a significant impact on the delinquent behavior of LBC; children whose fathers migrated and who were under the care of their mother engaged in more problematic behaviors (Chen and Jiang, 2019). Chen and colleagues reported that both parents being migrants was positively associated with children's social and academic competence but negatively associated with psychological issues and behaviors (Chen et al., 2019).

Chen and Jiang highlighted that caretaking practices shape the behavioral problems of LBC and found that children who had two migrant parents and whose grandparents cared for them engaged less in delinquent behaviors (Chen and Jiang, 2019), demonstrating that grandparents provide considerable caretaking to LBC (Gao et al., 2010; Fu and Zhu, 2020; Yang and Liu, 2020; Xiao et al., 2020). Children living with extended family and grandparents may experience strict observation and supervision (Chen and Jiang, 2019). In contrast, few studies have highlighted the emergence of delinquent behavior under the caretaking of grandparents (Gao et al., 2010; Jia and Tian, 2010). Perhaps the inadequacy of grandparents' education prevents them from providing proper guidance and support, and their caretaking is limited to material welfare and vulnerable health awareness (Gao et al., 2010; Jia and Tian, 2010; Chen et al., 2019). Recent media reports note that Chinese grandparents' aging factors (most under 60 years old living with LBC) were associated with vulnerable physical and mental health, and these grandparents were unable to provide proper caretaking and adequate supervision to LBC (Jia and Tian, 2010; Gao et al., 2010; All-China Women's Federation, 2013; Chen and Jiang, 2019; Hu et al., 2020; Yang and Liu, 2020).

Furthermore, grandparents' lack of academic skills limits their ability to cope with the needs of subsequent generations and adopt changing societal practices (Gao et al., 2010; Hu et al., 2019). Grandparents who receive remittances from migrant parents are able to spend less time on the burden of farming, allocate more time for LBC's health and safety, and improve the academic performance of LBC (Chen and Jiang, 2019; Fu and Zhu, 2020). Therefore, migrant parents' decision-making during bothor single-parent migration depends on the health status of the grandparents, which contributes to practical caretaking, strengthens the ability of migrant parents to stay away and is the best choice for migrant parents (Chen and Jiang, 2019). Grandparents' strong attachment and bonds with LBC can fill the physical gap between parents and LBC and reduce mental stress and depressive issues (Cuddeback, 2004; Yang and Liu, 2020).

As the pandemic continues to spread throughout the globe, our findings are increasingly relevant for other migrant parents who left their children behind for different reasons. LBC face psychological, academic, and parental guidance problems during 
this time of separation. In addition to LBC, migrant workers in China are undergoing severe problems and challenges during the pandemic (International Labor Organization, 2020; Tang and Li, 2021). Many migrant parents who had already left for Chinese spring festival celebrations became stuck in villages, while others were trapped in their workplaces and could not return to their hometowns (Tang and Li, 2021). As a result, these rural migrants encountered challenges that impacted material and nonmaterial aspects, particularly their LBC. Prior and recent studies have examined different aspects of LBC. Most studies have quantified their findings but cannot explain the phenomena in depth. Qualitative studies have sought to explore the issues through teachers and parental involvement to support LBC, which results in very little literature that assesses the experiences of LBC. Given the considerable complications involved, we sought LBC to thoroughly discuss their experiences of psychological, academic, and physical well-being during the COVID-19 pandemic.

\section{Methodology}

Limited studies have investigated migrants' and LBC's experiences in China during the COVID-19 pandemic. Some of these studies provided quantified accounts (Wang et al., 2021; Zhou et al., 2021), and a few have applied qualitative document analysis approaches and child experts' experiences during the COVID-19 pandemic and policy implementation (Zhao et al., 2021). One qualitative description explored the coping strategies of rural migrants trapped in urban areas (Tang and Li, 2021). Similarly, Wang's study explored the school and gender inequalities experienced by girls in rural areas during COVID-19 (Wang, 2020). The current study explored LBC's COVID-19 experience from word of mouth, which provides implications for countries still battling the pandemic. We adopted a qualitative research method that comprised face-to-face, in-depth interviews with LBC to collect the data needed for the current research (Zhang, 2018; Tang and Li, 2021).

\section{Participants}

The objective of the study was to investigate LBC's experience during COVID-19. Initially, the study aimed to target Province Y, located in the southwestern part of China, since the area is the origin of many migrant workers to other provinces due to poverty or a lack of job opportunities (Su et al., 2017, Zhang, 2018). After we obtained ethical approval from the first author's university, we visited rural primary and middle schools in the province to select volunteer students who claimed that one or both of their parents were interprovincial migrants for at least six months before the interview and who were not reunited with their parents during or after the COVID-19 pandemic. To conduct the face-to-face semistructured interviews, we purposely sampled LBC who were not reunited with their migrant parents during the epidemic (see Table 1). The first author had academic links with the schools' principals and teachers to locate LBC from different grade levels. Subsequently, the study identified $22 \mathrm{LBC}$ aged 10 to 15 years with a proportional gender ratio who met the 
study criteria and acquired signed consent or approval from their homestay parent or legal guardians (e.g., grandparents or relatives).

\section{Data-gathering Instrument}

Face-to-face semistructured interview strategies were adopted to obtain information on the participants' experiences. The interview questions were constructed in the English language; later, with the help of professional translation, we converted the interview questions into the Chinese (Mandarin) language to enable the respondents to share their accounts in their language and from their point of view. The first author is a native Chinese academic and psychologist originally from the target province; he had a complete understanding of the area dialects and experience counseling children with different challenges. The interviews were conducted in early May 2021. To ensure the trustworthiness of the interview findings, we adopted the probing questing tactic to ensure the reliability and accuracy of the accounts provided by the participants. This allowed the researcher to avoid vague points and obtain clarification of the participants' accounts. Furthermore, through a probing strategy, we allowed respondents to share their personal and vital accounts. At the beginning of the interview questions, we asked them to introduce themselves and be relaxed with us to develop trust.

\section{Procedure and Data Analysis}

We used the deductive thematic approach. This approach allows the researcher to analyze data with expected findings from the literature. Through a literature review, we analyzed LBC's problems and designed our interview questions to explore LBC's experiences during COVID-19. Interviews with each respondent were recoded and transcribed first into Chinese and then with a professional translator. Furthermore, with the assistance of the first author, we translated the interviews into the English language. Face-to-face semistructured interviews allowed us to obtain the respondents' facial expressions and emotional gestures at the time of the interview.

After the translation, the two other study authors developed familiarity with the interview transcript for our data analysis. While reading the transcript, we noted aspects of their experiences as they arose. Furthermore, the repeated reading led us to identify themes and relationships between themes for each transcript. Finally, after deeply examining each transcript, we compared themes across all transcripts to identify the differences and similarities. The analysis of the transcribed data and vigilant interpretation of these data led us to three themes: the psychological, academic, and physical well-being of these LBC. The preliminary findings indicated that regarding the migrant parents, five parents were divorced (see Table 1). Given that all migrant parents were away from their children for a long time, the interview data showed that grandparents were the immediate caretakers or legal guardians of the LBC. Only one female participated under the supervision of her school teacher; her father was a migrant, and she was unaware of her mother's status and existence. 


\section{Research Findings}

\subsection{COVID-19 and the Psychological State of LBC}

Regarding rural parental migration, remittance is the real incentive for parents and their left-behind children. Participants were aware of their parents' motives to move to an urban area to meet their family's necessities (Hu, 2019). These LBC already experienced feelings of stress and depression from the absence of their parents. Hence, this affected how they perceived COVID-19. While discussing COVID-19, our respondents shared interesting psychological streams that they encountered. S2 reported that.

"For me, COVID was just boring, nothing else. I was not afraid. At home, I look after my grandparents. They are very old. I look after my younger brother, too. No games and no fun. Just work and work."

Likewise, we can understand from all respondents that LBC were not afraid of COVID-19. Notably, not a single respondent revealed a state of fear and tension regarding COVID-19. S4 mentioned that.

"I do not think that COVID brings any change to me. I think there is no change. I will beat my sister. She bullies me... After the epidemic, I will not do housework for my grandmother... I am not afraid of COVID. I am tired of work and being bored at home. My parent's behavior is the same and not changed... just the same. She used to call us very often. She is busy. I do not want anything from them. Mostly my grandma advises me to study hard."

Regarding the psychological well-being and happiness of LBC, parent-child communication is the crucial aspect. In-stable parent-child communication leads to stress and aggressiveness. During COVID-19, these LBC were under the care of their grandparents due to age, and a lack of emotional attachment with them creates stressful and unhappy feelings among LBC. Respondent S5 mentioned that.

"...I feel sad that my friends are happy with their families and no issues with their study, their parents teach them and play with them, and they eat together. If my parents were around, I would be a good student like them...I was not afraid of COVID. I just want my parents to give me time and play with me. My mother used to call me every day, but I know she has to work hard to make money for us and my sister's fees." Likewise, S7 claimed that "COVID brought one change: they (parents) did not visit this year. I am not afraid of COVID. Just reading and staying at home is boring. I hope they will come back early and spend more time with me."

Respondent S22 remarked that COVID-19 made him experience loneliness and boredom at home and reported that "...no friends, no fun, no playing and no friend to guide me in studying. I miss my friends and games. At home, I just work and work 


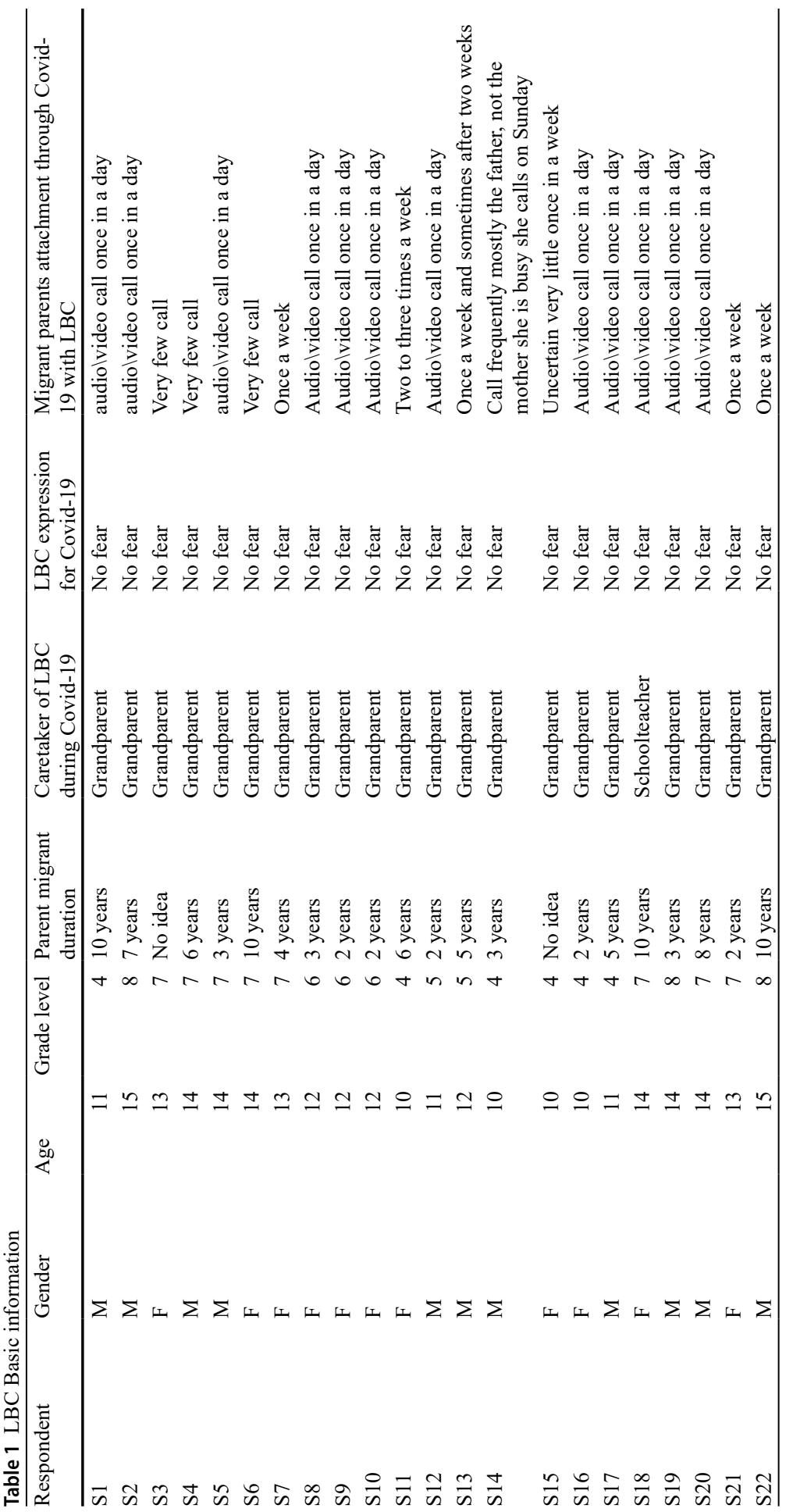


nothing else. I feel exhausted, lazy, and sad but I don't have a fear of COVID-19. It's just a sickness. I am afraid of staying at home with no school and no friends."

Respondents S5 and S7 allow us to understand that these LBC faced the epidemic with courage and had no stress. Nearly all the respondents claimed the same psychological state, but they mentioned that the epidemic was boring and primarily involved them staying at home.

Likewise, respondent S10 outlined that the epidemic had not increased his stress and was normal for him.

I was looking after myself and when my parents were in the city...they used to call me during COVID on video and telephone, and they just visited home mostly on Chinese New Year. There are no changes, and all is the same. They advise me to study hard, not go out, wash my hands, and put on a mask... I felt no fear from COVID, and I can even say that it was a boring time for me.

Respondent S1 outlined and added the following:

"My parents called us every night, and we talked to them, but they visit only once a year. Sometimes, when my brother broke his legs and another time when he broke his ankles, our parents had to visit and pay money for it... they visited us when something important happened to us... they took him to the doctor and looked after him for a few days. Later, when my brother broke the leg of one man, then they came again. I remember, and they paid money for it as a punishment. My brother used to hit people, and then they had to pay visits mostly due to him."

Table 2 LBC Psychological patterns

\begin{tabular}{|c|c|c|c|c|c|}
\hline Respondent & Sibling & Grade & Helping Grandparents & $\begin{array}{l}\text { LBCs' } \\
\text { Emotions }\end{array}$ & $\begin{array}{l}\text { Parental advice during } \\
\text { Covid }\end{array}$ \\
\hline S1 & 1 bro & 4 & $\begin{array}{l}\text { Cleaning and helping in } \\
\text { farming }\end{array}$ & $\begin{array}{l}\text { Sad and } \\
\text { unhappy }\end{array}$ & $\begin{array}{l}\text { Wear a mask and stay at } \\
\text { home }\end{array}$ \\
\hline S2 & 2 bro & 8 & $\begin{array}{l}\text { Cleaning and helping in } \\
\text { farming }\end{array}$ & $\begin{array}{l}\text { Sad and } \\
\text { unhappy }\end{array}$ & $\begin{array}{l}\text { Do not go out and stay } \\
\text { at home }\end{array}$ \\
\hline S4 & 2 sis & 7 & Cooking and cleaning & $\begin{array}{l}\text { Sad and } \\
\text { unhappy }\end{array}$ & Do not go out stay home \\
\hline S5 & 2 bro & 7 & Cooking and cleaning & $\begin{array}{l}\text { Sad and } \\
\text { unhappy }\end{array}$ & $\begin{array}{l}\text { Study hard, do not play } \\
\text { around }\end{array}$ \\
\hline S6 & 1 bro & 7 & $\begin{array}{l}\text { Cleaning and helping in } \\
\text { farming }\end{array}$ & Unhappy & $\begin{array}{l}\text { Study hard, do not play } \\
\text { around }\end{array}$ \\
\hline S7 & 1 bro & 7 & $\begin{array}{l}\text { Cleaning and helping in } \\
\text { farming }\end{array}$ & Unhappy & Keep safe \\
\hline S8 & No & 6 & Household and farming & $\begin{array}{l}\text { Sad and } \\
\text { bore }\end{array}$ & Wash hands often \\
\hline $\mathrm{S} 10$ & 1 bro & 6 & $\begin{array}{l}\text { Cleaning and helping in } \\
\text { farming }\end{array}$ & Unhappy & $\begin{array}{l}\text { Let me go to less crowded } \\
\text { places and take the mask }\end{array}$ \\
\hline S22 & No & 8 & Household and farming & Boring & $\begin{array}{l}\text { Help grandparents in } \\
\text { household and stay safe }\end{array}$ \\
\hline
\end{tabular}


As the respondents mentioned their diverse experiences (see Table 2 for more details) and their personal feelings toward the epidemic, most of them were not afraid of COVID-19 and were more engaged with households, even though a few of them mentioned that they felt tired and depressed due to these household obligations.

\subsection{COVID-19 and the Academics of LBC}

The Chinese Ministry of Education enacted policies to ensure education and launched initiatives to conduct online classes during COVID-19. However, in the beginning, providing visual aids to rural children who possessed inadequate resources and limited access to technology was a significant hindrance for the ministry. Later, the suggestion was to use all the visual aids available (TV, DingTalk, and WeChat) to smooth the learning process. Hence, online classes were successfully launched in rural areas. Our respondents shared their experiences with online classes with us. S2 mentioned the following:

“...during COVID-19, our school started online classes for us...I did not understand the teacher properly, I could not see the teacher or my friends, and I had to sit and just wait for the teacher to ask me a question. It bores me, and I lose my attention. Sometimes I totally forget what the teacher is saying and which class is going on. I feel like tape... and no one is there to teach me at home. My grandparents are farmers and old. If I helped them cook, clean and in the fields ...sometimes I cannot complete my homework."

Similarly, due to the online classes being boring, the entire interviewed group reported learning constraints. Besides, respondents mentioned that grandparents' poor health and aging and household obligations impacted their learning, as S2 mentioned. Respondent S22 stated the following.

“...Mostly, I study by myself and look after my grandma. She is blind, so I have to help her around the house (cooking, cleaning, and dishwashing). In addition, my grandpa is a farmer. He is old, and sometimes I helped him on the farm too... I get tired. When my online classes start, I feel sleepy and bored, and I do not understand what the teacher is saying. I try to listen but I cannot make it. For me, mathematics is very difficult. No one teaches at home. I feel sad if my father is there. Maybe he would help me but knows there is no one to help me."

In addition, few respondents emphasized the pace of online classes. S4 stated the following.

“...I feel it's difficult for me during online classes. I do not understand because it's very fast for me. If my parents are there, I do not have to work more, so I have time to study. No one is there to help me study...regarding my grandparents, I have to help them...because they are old." 
Likewise, besides these factors, respondent S18 reported the physical absence of fellows and class discussion and claimed the following.

"Ah...I feel alone and sad. It's boring to sit in front of the TV and listen to the teacher. I do not understand the teacher. It's very fast, and there is no discussion with friends. Just listen, listen and listen. I cannot talk to my friends. I miss my friends and our discussions."

Similarly, respondent S20 stated the following: "I feel that taking online classes is not as interesting as taking classes in classrooms. There are no friends and teachers, and it's just listening. I miss my friends... but I feel that taking classes online is more efficient during COVID-19 to keep studying."

Besides, one respondent whose mother was at home during COVID-19 shared her online class experience with us. S8 stated.

"During online classes, I learned a lot from my mother...she was helping me learn how to take notes, how to get help from the internet, and how to improve my learning...I am good at mathematics and Chinese only. My English is weak... I want to be a good student. My mother has a dream for me to study hard and achieve good grades."

"My parents were in Guangzhou during the COVID time. They used to call me once a week to ask about my grandparents and me, and mostly they advise me to help grandparents around the house and stay safe by not going out. I am used to listening to this advice for the last ten years. For me, nothing changes. All are same...yeah just wash hands and do not go out is new".

However, the interviews demonstrate that LBC having obligations to work for grandparents and siblings may impact their online learning. In addition, these household obligations and lack of time and energy make them concentrate less on studies. Furthermore, this increases their weary feelings.

Respondent S16 mentioned that.

"I feel brave, not afraid of COVID-19. I read at home, and that makes me feel brave. I enjoyed my online classes. The epidemic didn't change my relationship with my parents. They were always loving and caring for me, especially my dad. He very much considers my studies, and he used to teach me online on a video call. Whenever I encounter any problem, they listen to me and help me to solve it...."

Besides, respondent S13 mentioned that "I am good in academics. Even I can say that I am achieving high grades in my classes. I know I have to study hard and make good progress in achieving my parents' dreams that they advise me on."

Likewise, S15 adds that "My parents always advise me to study hard and read books. I am afraid of English, and it's very difficult for me...no one is there to teach me. Regarding online classes, I do not understand the teacher. My grandparents cannot help at home since they have no education...dad was not with me...normally, he 
does not call me since he is busy with work. If he was around, I wish he would guide me like my friend's parents who teach her and read stories for her. I feel sad and alone... when my friends get good grades, and I don't."

Concerning the online classes and academics, most respondents repeatedly mentioned their loss of attention due to the physical absence and their fellows (see Table 3 for more details). Consequently, they found it challenging to grasp the academic content. However, most of them were under the care of grandparents who were farmers and unable to provide academic assistance to these LBC.

\subsection{COVID-19 and Physical Well-being of LBCs}

Although we conducted a face-to-face interview with LBC, we observed that most LBC were thin, and while sharing their experiences, they had teary eyes and sad gestures. Moreover, some of them mentioned and shared their food and eating wishes with us.

S6 mentioned food as a constraint.

"I was not afraid, but my parents mostly advise me to stay at home instead of going to the street...when I was young, I was very excited when they visited me, we had good food...I was waiting for them to visit us...these days we have no food at home, grandparents are sick cannot work... during COVID-19 my parents had no job in the city, and we had very little money...my teacher and

Table 3 LBC Academic patterns

\begin{tabular}{|c|c|c|c|c|}
\hline Respondent & Grade & $\begin{array}{l}\text { Helping } \\
\text { Grandparents }\end{array}$ & $\begin{array}{l}\text { Weak in } \\
\text { Subject }\end{array}$ & $\begin{array}{l}\text { Online } \\
\text { classes } \\
\text { feedback }\end{array}$ \\
\hline S2 & 8 & $\begin{array}{l}\text { Cleaning and } \\
\text { helping in } \\
\text { farming }\end{array}$ & Mathematics & Boring \\
\hline S4 & 7 & $\begin{array}{l}\text { Cooking and } \\
\text { cleaning }\end{array}$ & Mathematics & Boring \\
\hline S8 & 6 & $\begin{array}{l}\text { Household and } \\
\text { farming }\end{array}$ & Mathematics & Boring \\
\hline S13 & 5 & $\begin{array}{l}\text { Household and } \\
\text { farming }\end{array}$ & Mathematics & $\begin{array}{l}\text { Difficult } \\
\text { and } \\
\text { boring }\end{array}$ \\
\hline S15 & 4 & $\begin{array}{l}\text { Cooking and } \\
\text { cleaning }\end{array}$ & English & $\begin{array}{l}\text { Very } \\
\text { difficult }\end{array}$ \\
\hline S16 & 4 & $\begin{array}{l}\text { Household and } \\
\text { farming }\end{array}$ & English & $\begin{array}{l}\text { Very } \\
\text { difficult }\end{array}$ \\
\hline S18 & 7 & $\begin{array}{l}\text { Cleaning and } \\
\text { helping in } \\
\text { farming }\end{array}$ & $\begin{array}{l}\text { No issue, I am } \\
\text { good }\end{array}$ & $\begin{array}{l}\text { Very } \\
\text { boring }\end{array}$ \\
\hline S 20 & 7 & $\begin{array}{l}\text { Household and } \\
\text { farming }\end{array}$ & $\begin{array}{l}\text { I am very } \\
\text { good at study }\end{array}$ & Boring \\
\hline S22 & 8 & $\begin{array}{l}\text { Household and } \\
\text { farming }\end{array}$ & Mathematics & Boring \\
\hline
\end{tabular}


my friends collected money to buy food for us when our parents did not send money."

Similarly, S16 mentioned that

Sometimes I wish we have good food and family time I wish to drink milk and have some snacks and eggs, but I know it's not possible. Parents are trying, but they do not have good jobs in COVID my mother get angry with us all time and used to fight with me on call. I know they left us for money, but we do not have money. Sometimes i think why they left us...

\section{Likewise, S1 shared that}

After they left us our finical situation gets better, and we have food to eat before it was not like this...Previously other people buy for us food and something to eat. I wish my parents earn lots of money to buy a car and come back soon and live with us... Now we do not have good food and grandmamma is sick, she cannot cook every time for us I miss my mother she used to cook for me porridge...

Besides, few LBCs shared with us their lifestyle and parents visited them $\mathrm{S} 3$ revealed that "During COVID I do not know where were they and I just saw my father last June he visited me, during COVID I was with grandparents, my father does not call mostly, but in COVID they called me every day and explained the situation and safety things and study hard mostly my father advise me. My mother I do not know where is she, my father education is primary level; he is working hard, so he does not have time to visit me but mostly when he visits, he buys me good food and clothes and stay a very short time with me. I know he left for money, I do not think he makes money. I am worried about him; he is the only one I have...He has no job these days...He called me and makes jokes, and my uncle helped me in my studies, but mostly my grandmother loves me, and she guided me for COVID safety."

"My parents are working hard for us because they are not educated enough, just junior primary school. They visit once in a year, then we eat good food and enjoy out on new year's. I feel so happy when they are around. But I think now things are changing I do not need them a lot." (S6).

"...But now I understand they are working hard for me. I get good food and milk, and soon they will buy me a good computer to study."(S7).

In addition, few LBCs mentioned that during COVID-19, their migrant parents and grandparents were advising them to stay safe and keep their hands clean, such as S8 marked that, "my grandma told me to stay healthy, I wash my hands and clean myself to stay safe from COVID." Similarly, S10 shared that "my parents advised me to stay at home and avoid the playing and crowds" (Table 4). 


\begin{tabular}{llllll}
\hline $\begin{array}{l}\text { Table 4 LBC Physical well- } \\
\text { being patterns }\end{array}$ & Respondent & Sibling & Grade & $\begin{array}{l}\text { Supply for } \\
\text { nutrition }\end{array}$ & $\begin{array}{l}\text { Grandpar- } \\
\text { ents Oc- } \\
\text { cupation }\end{array}$ \\
\hline & S1 & 1 bro & 4 & $\begin{array}{l}\text { Limited food } \\
\text { to eat } \\
\text { Limited food } \\
\text { to eat }\end{array}$ & Farming \\
S3 & 2 bro & 8 & Farming \\
S6 & 1 bro & 7 & $\begin{array}{l}\text { Sufficient food } \\
\text { (Vegetables) } \\
\text { to eat } \\
\text { Sufficient food } \\
\text { (Vegetables) }\end{array}$ & Farming \\
to eat \\
S7
\end{tabular}

\section{Discussion and Conclusion}

Our study is the first of its kind to collect data by directly interviewing left-behind rural children in China during the COVID-19 pandemic to explore their psychological, academic, and physical well-being. The literature claims that the pandemic was the most challenging period for children with difficulties (International Labor Organization, 2020; Tang and Li, 2021). According to the analyses, we categorized the data into three sections: the psychological, academic, and physical well-being of LBC during the pandemic.

\section{Psychological Adjustment of LBC}

Similar to previous evidence, almost all of our respondents had emotional and psychological adjustment difficulties during the pandemic (Jia and Tian, 2010; Fu and Zhu, 2020; Guan and Deng, 2019; Gao et al., 2010; Liu et al., 2020; Liu et al., 2021). Long parental absences during the epidemic, lockdown, and limited social interaction led to severe psychological states of sadness, depression, and feelings of loneliness among LBC (Graham and Jordan, 2011; Jia and Tian, 2010; Lei et al., 2020). Being left behind and feeling lonely had adverse impacts on their well-being (Jia and Tian, 2010; Zhang, 2019; Liu et al., 2020; Shi et al., 2021). Unexpectedly, we found that LBC were not afraid of COVID-19, contrary to a previous study (Chi et al., 2021). A possible explanation for this finding is that the lack of parental communication and lack of awareness regarding the epidemic led to less fear; furthermore, these children may be more exposed to threats in their lives, and difficulties make their behavior stronger rather than making them afraid (Mu and $\mathrm{Hu}, 2016$; Chen and Jiang, 2019; Yang and Liu, 2020). Our evidence demonstrates that a long duration of parental migration negatively impacts parent-child relationships; this is a prominent issue during the pandemic, when children need their parents to look after them. However, 
our findings show that most participants claimed that they no longer needed their migrant parents, which reflects their mental health and loss of hope in their parents. In contrast, previous studies have claimed that LBC wish to see their parents (Wang et al., 2019; Liu et al., 2020; Shi et al., 2021). Moreover, grandparents' caretaking cannot replace the lack of parental affection and attachment due to the grandparents' age, outdated information and generation gap. These grandparents are not sufficiently strong to care for $\mathrm{LBC}$, and their aging and poor health are a cause of stress and a physical burden for LBC. LBC claim that their grandparents' poor health forces them to work in the fields and occupies their study time (Chen and Jiang, 2019; Hu et al., 2020; Gao et al., 2010; Yang and Liu, 2020). Playing with peers, running, and climbing trees and mountains are the primary sources of entertainment of these rural LBC (Chen et al., 2019). However, the pandemic limits the physical activities of LBC, which is the primary cause of their sadness and depression. Our study found that during COVID-19, LBC have experienced extreme loneness and depression, which leads them to claim that they no longer need their parents. Furthermore, their lack of fear of COVID-19 was a surprising finding.

\section{Academic Adjustment of LBC}

Several studies have shown that LBC's underachievement results from parental absence (Wang, 2014; Fu et al., 2017; Wu and Zhang, 2017; Hu et al., 2020; Hou et al., 2020; Mao et al., 2020; Liu et al., 2021). Our analysis found that during the pandemic, parental absence was a major challenge for LBC. In particular, taking online classes due to household obligations and providing hands-on help in the fields for grandparents were obstacles for LBC. As a result, most LBC found online classes to be stressful. Furthermore, most LBC were under the care of their grandparents and had no opportunities to interact with peers and friends due to social distance during the COVID-19 outbreak and were unable to have academic discussions or support. In addition, physical fatigue among LBC leads to a loss of attention in online classes (Cuong and Linh, 2015; Fu et al., 2017; Xiaofeng et al., 2018; Liu et al., 2020; Liu et al., 2021; Mao et al., 2020). Moreover, unhealthy food consumption leads to academic challenges for these LBC (Tian et al., 2017). Notably, regarding the online learning of LBC, inadequate parental academic guidance and proper use of social media for academic purposes also have substantial negative impacts on LBC's academic work (97), particularly in mathematics and complex English subjects (Xiaofeng et al., 2018). These subjects require students to have additional support and guidance to perform well. However, their caretakers' limited educational background and insufficient peer support made these LBC suffer more in these subjects during the pandemic. With regard to academic obstacles, most participants noted that the reasons for their lack of attention were the pace of teaching instruction and the lack of activities with online student involvement and peer interaction opportunities during online classes (Zhang et al., 2014; Fu et al., 2017). Ultimately, the analytical evidence indicates that a lack of parental guidance, an inadequate educational environment at home, and insufficient online class teaching strategies determine their lower academic perfor- 
mance. Moreover, LBC suffer academically due to a lack of parental guidance, social interaction, and help from peers, which limits their academic progress.

\section{The Physical Well-Being of LBC During COVID-19}

In the analysis of the data, we observed that food was a constraint for LBC during the COVID-19 pandemic. Social lockdown during the pandemic prevented migrant parents from obtaining daily wages, which made their LBC suffer from nutritional deficiencies. During our interviews, we observed that most LBC were skinny, pale, and sad (Gao et al., 2010; Zhang, 2018; Lei et al., 2020). Some of the respondents cried while sharing their experiences and life tragedies with us. The sad faces and stressrelated gestures of these LBC reflected their daily life challenges. In addition, in the interview transcripts, we repeatedly observed the wish for nutritional food such as milk and eggs. The food insecurity of these LBC leads to depression, and depression influences their educational performance and engagement (Chen and Jiang, 2019; Zhang and Yang, 2019; Fu and Zhu, 2020).

Regarding another aspect of the physical well-being of $\mathrm{LBC}$, the present study found that dual parental absence and a lack of communication with LBC resulted in a high risk of outdoor activities by LBC involving physical injuries (Jia and Tian, 2010; Liang et al., 2017; Wu and Zhang, 2017). When both parents are migrants, the supervision of LBC falls on the shoulders of weak and old grandparents who cannot monitor LBC's activity. Since farming is the fundamental occupation of their grandparents, LBC are required to help their grandparents in farming, which causes physical fatigue and weakness. In addition, the most frequently consumed daily food for LBC is vegetables; we found that they wished for food with protein and calcium. Furthermore, the poor health status and aging of grandparents puts household and cooking pressure on the children's shoulders, leading to physical injuries (Zhang et al., 2014; Chen et al., 2019; Shi et al., 2021). Early studies found that remittances support the educational expenses of $\mathrm{LBC}$, but most migrant parents were unable to provide remittances due to COVID-19 and were in poor conditions during the lockdowns (Hou et al., 2020; Tang and Li, 2021).

\section{Implications and Limitations}

Globally and within China, the pandemic is ongoing. In light of our study findings, we present robust, practical implications for improving the psychological and academic challenges of LBC, especially during the post-COVID-19 period. Hence, the present study suggests that public health institutions and nongovernmental organizations should provide counseling and awareness regarding COVID-19 to LBC and other vulnerable children by ensuring their nutritional and health well-being. Moreover, to improve the effectiveness of online classes, schools and teachers should modify their teaching styles from lecture-oriented to student-oriented teaching and develop interactive online classes where all students can communicate and share information with peers and teachers. Health and nutrition supervision should be provided to 
caretakers or grandparents to prevent pandemic side effects. In addition, migrant parents should regularly contact LBC, provide them with social support, awareness, and guidance regarding COVID-19 and try to compensate for physical absence through social media and daily contact to avoid psychological problems such as depression and loneliness in LBC.

The present exploratory study has two significant limitations. The first limitation is that this qualitative study used face-to-face interviews with LBC situated in Y Province of southwestern China, so the study's findings can be generalized only to the specific LBC groups in the target province. Second, the current study could not interview migrant parents, legal guardians (grandparents, relatives), or teachers to triangulate their responses with the responses of LBC. Thus, the present study encourages future qualitative studies to understand the other side of the story, which most studies neglect.

Acknowledgements We would like to express our great appreciation and admiration to adorable children who were a part of this study and their parents and teachers who made the data collection happen.

Author Contributions SK and ET conceived the study, participated in its design, carried out the study, performed the statistical analysis, and drafted the manuscript. SK and CG supervised the study, participated in the study's design, and helped draft the manuscript. CG administered the interview in the Mandarin language and critically revised the manuscript. All authors read and approved the final manuscript.

Funding No financial support was obtained for this study.

Availability of Data and Materials All datasets collected from our participants can be provided based on the request.

\section{Declarations}

Conflict of Interest The authors declare that the research was conducted without any commercial or financial relationships that could be construed as a potential conflict of interest.

Ethnic Statement All participants' legal guardians had signed approval consent before the interview, which the first ethical committee gave. The interviewer (psychologist) kept the comfort zone with each interviewee, and we considered ethical norms and their data would be protected and used for scientific research.

Consent for Publication Not applicable.

\section{References}

Bai, Y., Zhang, L., Liu, C., Shi, Y., Mao, D., \& Rozelle, S. (2018). Effect of parental migration on the academic performance of left-behind children in North-Western China. The Journal of Development Studies, 54(7), 1154-1170

Caron, R., Poitras, K., St-Laurent, D., Joly, M. P., Poirier, M. A., Berthelot, N., \& Dubois-Comtois, K. (2021). Foster family assessment: The assessor's perspective-A qualitative study. Child Abuse \& Neglect, 105362

Chen, Q., Sun, X., Xie, Q., Li, J., \& Chan, K. L. (2019). The impacts of internal migration on child victimization in China: A meta-analysis. Trauma, Violence, \& Abuse, 20(1), 40-50 
Chen, X., \& Jiang, X. (2019). Are grandparents better caretakers? Parental migration, caretaking arrangements, children's self-control, and delinquency in rural China. Crime \& Delinquency, 65(8), 1123-1148

Chi, X., Liang, K., Chen, S. T., Huang, Q., Huang, L., Yu, Q. ... Zou, L. (2021). Mental health problems among Chinese adolescents during the COVID-19: The importance of nutrition and physical activity. International journal of clinical and health psychology: IJCHP, 21(3), 100218. https://doi. org/10.1016/j.ijchp.2020.100218

Cuddeback, G. S. (2004). Kinship family foster care: A methodological and substantive synthesis of research. Children and youth services review, 26(7), 623-639

Cuong, N. V., \& Linh, V. H. (2015). Should Parents Work Away from or Close to Home?. The Effect of Parental Absence on Children's Time Use in Vietnam. Journal of Human Development and Capabilities. https://doi.org/10.1080/19452829.2015.1103711

Fan, X., \& Chen, M. (2001). Parental involvement and students' academic achievement: A meta-analysis. Educational psychology review, 13(1), 1-22

Fontanesi, L., Marchetti, D., Mazza, C., Di Giandomenico, S., Roma, P., \& Verrocchio, M. C. (2020). The effect of the COVID-19 lockdown on parents: A call to adopt urgent measures. Psychological Trauma: Theory, Research, Practice, and Policy

Fu, L., \& Zhu, Y. (2020). Are rural children of work-away parents left behind? Voices from rural teachers. Children and Youth Services Review, 117, 105269

Fu, M., Bo, W. V., Xue, Y., \& Yuan, T. F. (2017, August). Parental absence accompanies worse academic achievements: Evidence-based upon a sample of left-behind children in rural China. Frontiers in Education (Vol. 2, p. 38). Frontiers

Gao, Y., Li, L. P., Kim, J. H., Congdon, N., Lau, J., \& Griffiths, S. (2010). The impact of parental migration on health status and health behaviours among left behind adolescent school children in China. $B M C$ Public Health, 10(1), 1-10

Gaydosh, L. (2015). Childhood risk of parental absence in Tanzania. Demography, 52(4), 1121-1146

Graham, E., \& Jordan, L. P. (2011). Migrant parents and the psychological well-being of left-behind children in Southeast Asia. Journal of Marriage and Family, 73(4), 763-787

Guan, S., \& Deng, G. (2019). Whole-community intervention for left-behind children in rural China. Children and Youth Services Review, 101, 1-11

Hou, W. P., Tan, T. X., Wen, Y. J., Wang, X. Q., Li, X. B., \& Wang, C. Y. (2020). The effect of increased family finance and dual-parental absence since infancy on Children's Cognitive abilities. Social Science \& Medicine, 266, 113361

Hu, B. Y., Wu, H., Winsler, A., Fan, X., \& Song, Z. (2020). Parent migration and rural preschool children's early academic and social skill trajectories in China: Are 'left-behind children really left behind? Early Childhood Research Quarterly, 51, 317-328

$\mathrm{Hu}$, S. (2019). "It's for our education": Perception of parental migration and resilience among left-behind children in rural China. Social Indicators Research, 145(2), 641-661

Hu, Y. (2016). Impact of rural-to-urban migration on family and gender values in China. Asian Population Studies, 12(3), 251-272

Jia, Z., \& Tian, W. (2010). Loneliness of left-behind children: a cross-sectional survey in a sample of rural China. Child: Care, Health and Development, 36(6), 812-817

Jingzhong, Y., \& Lu, P. (2011). Differentiated childhoods: impacts of rural labor migration on left-behind children in China. The Journal of Peasant Studies, 38(2), 355-377

Lei, L., Desai, S., \& Chen, F. (2020). Fathers' migration and nutritional status of children in India: Do the effects vary by community context? Demographic Research, 43, 545-580

Li, W., Wang, Z., Wang, G., Ip, P., Sun, X., Jiang, Y., \& Jiang, F. (2021). Socioeconomic inequality in child mental health during the COVID-19 pandemic: First evidence from China. Journal of Affective Disorders, 287, 8-14. https://doi.org/10.1016/j.jad.2021.03.009

Liang, Y., Wang, L., \& Rui, G. (2017). Depression among left-behind children in China. Journal of Health Psychology, 22(14), 1897-1905

Liu, H., Chang, F., Corn, H., Zhang, Y., \& Shi, Y. (2021). The impact of parental migration on non-cognitive abilities of left-behind children in northwestern China. Journal of Asian Economics, 72, 101261

Liu, H., Liu, L., \& Jin, X. (2020). The Impact of Parental Remote Migration and Parent-Child Relation Types on the Psychological Resilience of Rural Left-Behind Children in China. International Journal of Environmental Research and Public Health, 17(15), 5388

Lu, Y., Yeung, J. W. J., Liu, J., \& Treiman, D. J. (2019). Migration and children's psychosocial development in China: When and why migration matters. Social Science Research, 77, 130-147 
Mao, M., Zang, L., \& Zhang, H. (2020). The Effects of Parental Absence on Children Development: Evidence from Left-Behind Children in China. International Journal of Environmental Research and Public Health, 17(18), 6770

Meyerhoefer, C. D., \& Chen, C. J. (2011). The effect of parental labor migration on children's educational progress in rural China. Review of Economics of the Household, 9(3), 379-396

Mu, G. M., \& Hu, Y. (2016). Living with vulnerabilities and opportunities in a migration context: Floating children and left-behind children in China. Springer

Patrick, M. E., \& Schulenberg, J. E. (2014). Prevalence and predictors of adolescent alcohol use and binge drinking in the United States. Alcohol Research: Current Reviews, 35(2), 193-200

Shi, H., Wang, Y., Li, M., Tan, C., Zhao, C., Huang, X. ... Zhang, J. (2021). Impact of parent-child separation on children's social-emotional development: a cross-sectional study of left-behind children in poor rural areas of China. BMC Public Health, 21(1), 1-10

Su, S., Li, X., Lin, D., \& Zhu, M. (2017). Future orientation, social support, and psychological adjustment among left-behind children in rural China: A longitudinal study. Frontiers in Psychology, 8, 1309

Tang, S., \& Li, X. (2021). Responding to the pandemic as a family unit: social impacts of COVID-19 on rural migrants in China and their coping strategies. Humanities and Social Sciences Communications, 8(1), 1-11

Tang, S., Xiang, M., Cheung, T., \& Xiang, Y. T. (2021). Mental health and its correlates among children and adolescents during COVID-19 school closure: The importance of parent-child discussion. Journal of Affective Disorders, 279, 353-360. https://doi.org/10.1016/j.jad.2020.10.016

Tian, X., Ding, C., Shen, C., \& Wang, H. (2017). Does parental migration have a negative impact on the growth of left-behind children?-New evidence from longitudinal data in rural China. International Journal of Environmental Research and Public Health, 14(11), 1308

Wang, J. (2020). Left Behind by COVID-19: Experiences of "Left-Behind" Girls in Rural China. Girlhood Studies, 13(3), 17-31

Wang, S. X. (2014). The effect of parental migration on the educational attainment of their left-behind children in rural China. The BE Journal of Economic Analysis \& Policy, 14(3), 1037-1080

Wang, Y. Y., Xiao, L., Rao, W. W., Chai, J. X., Zhang, S. F., Ng, C. H. ... Xiang, Y. T. (2019). The prevalence of depressive symptoms in 'left-behind children in China: a meta-analysis of comparative studies and epidemiological surveys. Journal of Affective Disorders, 244, 209-216

Wang, Y., Liu, W., Wang, W., Lin, S., Lin, D., \& Wang, H. (2021). Left-behind children's social adjustment and relationship with parental coping with children's negative emotions during the COVID-19 pandemic in China. International Journal of Psychology

Wen, M., \& Lin, D. (2012). Child development in rural China: Children left behind by their migrant parents and children of non-migrant families. Child Development, 83(1), 120-136

Wu, J., \& Zhang, J. (2017). The effect of parental absence on child development in rural China. Asian Economic Policy Review, 12(1), 117-134

Xiaofeng, M., Wenhui, D., \& Aibao, Z. (2018, September). The link between parental absence and poor reading comprehension: evidence from the left-behind children in rural China. In Frontiers in Education (Vol. 3, p. 71). Frontiers

Xiao, Y., Chen, Y., Chang, W., Pu, Y., Chen, X., Guo, J., \& Yin, F. (2020). Perceived social support and suicide ideation in Chinese rural left-behind children: a possible mediating role of depression. Journal of affective disorders, 261, 198-203

Yang, F., \& Liu, X. (2020). Grandparenting styles, childhood food insecurity, and depression among Chinese rural left-behind children: A structural equation model. Children and Youth Services Review, 119,105648

Zhang, H. (2018). A qualitative study on the rights of rural left-behind children in Sichuan Province, China. Children and Youth Services Review, 95, 12-18

Zhang, H., Behrman, J. R., Fan, C. S., Wei, X., \& Zhang, J. (2014). Does parental absence reduce cognitive achievements? Evidence from rural China. Journal of Development Economics, 111, 181-195

Zhang, H., Chi, P., Long, H., \& Ren, X. (2019). Bullying victimization and depression among left-behind children in rural China: Roles of self-compassion and hope (96 vol., p. 104072). Child abuse \& neglect

Zhang, L., \& Yang, F. (2019). Food insecurity and school performance among the left-behind children in rural China: Depression and educational expectation as mediators. School Psychology International, 40(5), 510-524. https://doi.org/10.1177/0143034319869048

Zhao, F., Zhu, N., \& Hämäläinen, J. (2021). Protection of Children in Difficulty in China during the COVID-19 Pandemic. Sustainability, 13(1), 279 
Zhou, C., Lv, Q., Yang, N., \& Wang, F. (2021). Left-Behind Children, Parent-Child Communication and Psychological Resilience: A Structural Equation Modeling Analysis. International Journal of Environmental Research and Public Health, 18(10), 5123

Zhou, C., Sylvia, S., Zhang, L., Luo, R., Yi, H., Liu, C. ... Rozelle, S. (2015). China's left-behind children: Impact of parental migration on health, nutrition, and educational outcomes. Health Affairs, 34(11), 1964-1971

Publisher's Note Springer Nature remains neutral with regard to jurisdictional claims in published maps and institutional affiliations. 